\title{
Prevalence of Depressive IIIness Among Patients with Asthmatic Disease Attending the University of Port Harcourt Teaching Hospital (UPTH)
}

\author{
Nkporbu Aborlo Kennedy ${ }^{1,}$, Ojule Inumanye Nkechi ${ }^{2}$, Stanley Princewill Chukwuemeka ${ }^{1}$ \\ ${ }^{1}$ Department of Neuropsychiatry, University of Port Harcourt Teaching Hospital, Port Harcourt, Nigeria \\ ${ }^{2}$ Department of Preventive and Social Medicine, University of Port Harcourt Teaching Hospital, Port Harcourt, Nigeria
}

Email address:

nakpigi2008@yahoo.com (N. A. Kennedy)

\section{To cite this article:}

Nkporbu Aborlo Kennedy, Ojule Inumanye Nkechi, Stanley Princewill Chukwuemeka. Prevalence of Depressive Illness Among Patients with Asthmatic Disease Attending the University of Port Harcourt Teaching Hospital (UPTH). American Journal of Psychiatry and Neuroscience. Vol. 4, No. 1, 2016, pp. 13-17. doi: 10.11648/j.ajpn.20160401.13

\begin{abstract}
Asthmatic disease is a chronic distressing respiratory disease. Many sufferers of asthmatic diseases tend to have co morbid depressive illness of variable severity due to the psychological/emotional burden associated with the disease. There is currently a paucity of data on the exact prevalence of depressive illness associated with patients with Asthma in this environment. The aim of this study was to determine the prevalence of depressive illness in patients with asthmatic disease attending the University of Port Harcourt Teaching Hospital (UPTH). Consent for the study was obtained from the Ethical Committee of the hospital. Patients for the study were recruited from different departments of the hospital. Asthmatics patients recruited were only those diagnosed by Consultant Physicians in the Departments of study, who have been on treatment for at least a period of 6 months. Also, subjects whose psychiatric illness preceded the asthmatic disease were equally excluded from the study. A socio-demographic questionnaire as well as the Beck's Depressive Inventory (BDI) was used as study instruments. The data obtained were analyzed using the SPSS version 20. Confidence interval was set at $95 \%$ and a $\mathrm{P}$ value of less than 0.05 was considered statistically significant. A total of 46 patients were enlisted into the study. Out of the total number of 46 patients, 31(67.4\%) of them were found to have depressive illness (56\% mild, 29\% moderate and 15\% had major depressive illness). Five patients representing $10.9 \%$ had suicidal ideation and $2(4.3 \%)$ had actually attempted at least on two occasions. $65 \%$ mostly of the mild depressive illness were not aware of their mental ill-health. Only $9 \%$ of those who were aware of their psychiatric condition had sought psychiatric intervention. From the study, the prevalence of depressive illness among asthmatic patients in UPTH is high and many of the patients appear unfortunately not to receive appropriately treatment as diagnosis and referral are still relatively inadequate and imprecise. There is therefore, great need for awareness of the existence of this comorbidity as well as institution of appropriate identification measures and subsequent referral for appropriate treatment. This will undoubtedly improve the management of asthmatics as well as their quality of life.
\end{abstract}

Keywords: Prevalence, Depressive Illness, Asthmatic Disease, UPTH

\section{Introduction}

Asthmatic disease is a chronic distressing respiratory disease. It can occur in all ages. It is inheritable but can be largely caused, precipitated and/or maintained by a number of environmental factors such as nature of occupation, inhaled substances including dust and other toxicants, and stress.

Asthma remains one of the most prevalent chronic respiratory disorders, affecting 100-150 million people worldwide $[1,2]$. The cost of caring for asthma has been calculated by the World Health Organization to exceed that of AIDS/HIV and tuberculosis combined. [1] These figures highlight the scope of the burden associated with this disease and its impact on emotion and quality of life. The high burden of asthma appears to be related to poor asthma control, which is associated with more frequent asthma symptomatology (dyspnea, wheezing, nocturnal waking symptoms), bronchodilator use, functional impairment (absenteeism, marked reduction in participation in social and physical activities), and worse pulmonary function [3, 4].

The American Thoracic society recommendations state that to make a diagnosis of asthma, a clinician should 
determine (1) the presence of episodic symptoms of airflow obstruction, (2) that airflow obstruction is at least partially reversible, and (3) that alternative diagnoses are excluded. Recommended methods for diagnosis include the following: (1) detailed medical history; (2) physical examination focusing on the upper respiratory tract, chest, and skin; and (3) Spirometry to demonstrate reversibility of airflow obstruction. Spirometry measurement before and after the patient inhales a short-acting bronchodilator is recommended for patients with a possible diagnosis of asthma, as this procedure helps to determine whether there is airflow obstruction and whether it is reversible over the short-term. A negative result helps to rule out asthma, although no single test is adequate to definitively diagnose asthma.

Several psychosocial and emotional factors have been found to be associated with poor asthma control and worse asthmarelated quality of life, including anxiety, depression, and inappropriate (e. g., avoidant) coping skills [5-10]. However, relatively few studies have evaluated the impact of chronic psychopathology, i. e., psychiatric disorders, on levels of asthma control and quality of life. Interestingly, rates of certain psychiatric disorders (e. g., panic disorder, major depression) among asthmatics have been reported to be at least double those observed in the general population, [7, 10-14] suggesting a need to better understand the impact of such disorders on levels of asthma control and related outcomes.

Depressive illness is a mood disorder characterized by core symptoms of low mood, loss of interest, reduced energy level, impairment in social, occupational and interpersonal functions. It may be mild, moderate or severe with or without psychotic features. Many sufferers of asthmatic diseases tend to have co morbid depressive illness of variable severity due to the psychological/emotional burden associated with the disease. There is currently a paucity of data on the exact prevalence of depressive illness associated with patients with Asthma in this environment.

The severity of psychiatric comorbidity is reportedly correlate with the severity of asthma symptoms, impaired functioning and poorer adherence to treatment regimens. However, the psychological and physical mechanisms underlying psychiatric comorbidity in asthma are not well understood. It remains unclear to what extent underlying psychological factors such as personality traits and their cognitive and behavioral correlates explain the presence of psychiatric comorbidities among children with asthma.

Neuroticism is a personality trait manifested as the tendency to experience negative and distressing emotions, and is reportedly linked to psychiatric morbidity including anxiety, depression, and stress susceptibility, as well as exacerbation of asthma.

Perceived stress in relation to life events is a cognitive correlate of neuroticism that is determined by one's own belief values, and conditioning. According to reports, stress has negative impact on the onset, severity, hospitalization, prolonged medication use, and prognosis of asthma. The presence neuroticism and perceived stress may therefore explain an excess of psychiatric comorbidities among asthma patients. At the same time, studies suggest that neuroticism and perceived stress also contribute to higher body mass index (BMI) or obesity and poor perceived health. These physical factors are also reportedly associated with asthma relapse and more severe and anxiety symptoms in asthma patients.

Although the temporal causal relationships are not well established, it is therefore possible that the excess of psychiatric morbidity associated with asthma could be due to the individual or combined effects over weight-obesity, perceived health status, stress, and neuroticism.

Given that asthma can be well controlled for the majority of patients, $[15,16]$ identifying those patients who may be at greater risk for poorly controlled asthma and, labouring under severe emotional trauma, worse quality of life therefore represents an important goal for clinical research.

\section{Aims and Objectives}

The aim of this study was to determine the prevalence of depressive illness in patients with asthmatic disease attending the University of Port Harcourt Teaching Hospital (UPTH).

\section{Methodology}

Consent for the study was obtained from the Ethical Committee of the hospital. Patients for the study were recruited from the Accident and Emergency Department, the Respiratory Units of Internal Medicine, Family Medicine and Pediatrics respective Departments. All asthmatic patients with another medical disease were excluded from the study. Asthmatics patients recruited were only those diagnosed by Consultant Physicians in the Departments of study, who have been on treatment for at least a period of 6 months. Subjects whose psychiatric illness preceded the asthmatic disease were equally excluded from the study.

A socio-demographic questionnaire as well as the Beck's Depressive Inventory (BDI) was used as study instruments. The data obtained were analyzed using the SPSS version 20. Confidence interval was set at $95 \%$ and a $\mathrm{P}$ value of less than 0.05 was considered statistically significant.

\section{Results}

A total of 46 patients were enlisted into the study, 27 males and 19 females. The average age was $28.6 \pm 2$ years. $57 \%$ were students of which $68 \%$ of them were of tertiary institutions. Out of the total number of 46 patients, $31(67.4 \%)$ of them were found to have depressive illness (56\% mild, $29 \%$ moderate and $15 \%$ had major depressive illness). Five patients representing $10.9 \%$ had suicidal ideation and $2(4.3 \%)$ had actually attempted at least on two occasions. Sixty-five percent mostly of the mild depressive illness were not aware of their mental ill-health. Sociodemorgraphic characteristics that were statistically significant were age $(\mathrm{p}=0.001)$, marital status $(\mathrm{p}=0.002)$, education $(\mathrm{p}=0.001)$, and occupation $(\mathrm{p}=0.003)$. Only $9 \%$ of those who were aware of their psychiatric condition had sought psychiatric intervention. See Table 1. 
Table 1. Diagnosis and Sociodemorgraphic Variables of Subjects.

\begin{tabular}{|c|c|c|c|c|}
\hline Variable & Total & $\begin{array}{l}\text { No. without } \\
\text { psychiatric } \\
\text { diagnosis }\end{array}$ & $\begin{array}{l}\text { No with } \\
\text { depressive } \\
\text { illness }\end{array}$ & $\begin{array}{l}\text { Statistical } \\
\text { analysis }\end{array}$ \\
\hline \multicolumn{5}{|l|}{ Age } \\
\hline $10-19$ & 15 & $3(6.5 \%)$ & $12(26.1 \%)$ & $\begin{array}{l}X^{2} \\
150.83\end{array}$ \\
\hline $20-29$ & 18 & $2(4.3 \%)$ & $16(34.8 \%)$ & $\mathrm{df}=4$ \\
\hline $30-39$ & 7 & $5(10.9 \%)$ & $2(4.3 \%)$ & $\mathrm{p}=0.001$ \\
\hline $40-49$ & 6 & $5(10.9 \%)$ & $1(2.2 \%)$ & \\
\hline Gender & & & & $X^{2}=0.73$ \\
\hline Male & 27 & $11(26.1 \%)$ & $16(34.8 \%)$ & $\mathrm{df}=1$ \\
\hline Female & 19 & $4(8.7 \%)$ & $15(32.1 \%)$ & $\mathrm{p}=0.39$ \\
\hline \multicolumn{5}{|l|}{ Marital status } \\
\hline Single & 22 & $5(10.9 \%)$ & $17(37 \%)$ & $X^{2}=41.72$ \\
\hline Married & 16 & $4(8.7 \%)$ & $12(26.1 \%)$ & $\mathrm{df}=4$ \\
\hline Widowed & 3 & $2(4.3 \%)$ & $1(2.2 \%)$ & $\mathrm{p}=0.002$ \\
\hline Divorce & 4 & $3(6.5 \%)$ & $1(2.2 \%)$ & \\
\hline Separated & 1 & & & \\
\hline \multicolumn{5}{|l|}{ Education } \\
\hline 10 & 9 & $3(6.5 \%)$ & $6(13 \%)$ & $X^{2}=20.64$ \\
\hline 20 & 14 & $5(10.9 \%)$ & $9(19.7 \%)$ & $\mathrm{df}=3$ \\
\hline 30 & 22 & $6(13 \%)$ & $16(34.8 \%)$ & $\mathrm{p}=0.001$ \\
\hline None & 1 & $1(2.2 \%)$ & $0(0 \%)$ & \\
\hline Duration & & & & $X^{2}=17.97$ \\
\hline $0-10$ & 9 & $4(8.7 \%)$ & $5(10.9 \%)$ & $\mathrm{df}=6$ \\
\hline $11-20$ & 17 & $3(6.5 \%)$ & $14(30.4 \%)$ & $p=0.006$ \\
\hline $21-30$ & 12 & $4(8.7 \%)$ & $8(17.4 \%)$ & \\
\hline$>30 \mathrm{yrs}$ & 8 & $4(8.7 \%)$ & $4(8.7 \%)$ & \\
\hline \multicolumn{5}{|l|}{ Occupation } \\
\hline Professional & 3 & $2(4.3 \%)$ & $1(2.2 \%)$ & $X^{2}=64.47$ \\
\hline Technician/Clerk & 5 & $2(4.3 \%)$ & $3(6.5 \%)$ & $\mathrm{df}=10$ \\
\hline Craft related & 8 & $3(6.5 \%)$ & $5(10.9 \%)$ & $p=0.003$ \\
\hline Elementary & 9 & $3(6.5 \%)$ & $6(13 \%)$ & \\
\hline Students & 20 & $4(8.7 \%)$ & $16(34 \%)$ & \\
\hline Armed forces & 1 & $1(8.7 \%)$ & $0(0 \%)$ & \\
\hline
\end{tabular}

\section{Discussion}

Asthmatic disease is a chronic medical disease. It is distressing, incapacitating and requires long term medication use. As such the psychological burden associated with the disease are enormous. The mere thought of the Long term duration of and continuous use of medications, functional incapacitations, the embarrassing tendency, and the financial implications of the disease are all sufficient reasons for possible development of depression. A link has been documented between corticosteroids, use in the management of asthma, and the development of depression.

Moreover, rates of certain psychiatric disorders, including panic disorder and major depressive disorder, were as much as six times more prevalent among asthmatics relative to the general population $[17,18]$. These findings are consistent with previous reports suggesting a high rate of psychiatric disorders, particularly mood (range 14-41\%) [7, 10, 12, 13] and anxiety (range 9-24\%) [11-13, 19] disorders, among adult asthmatics.

This study is consistent with the relatively few studies finding associations between actual psychiatric disorders and asthma morbidity, including worse asthma control and adherence to inhaled steroids ${ }^{6}$ and worse quality of life [7]. However, the present study strengthens previous reports by finding associations between psychiatric disorders and worse asthma control and quality of life independent of asthma severity. It (so strengthens previous reports by including a large sample size (over 400) of adult asthmatics with confirmed asthma. Previous studies assessing the prevalence of psychiatric disorders either had small sample sizes (less than 110), [6, 10-12] did not include assessments of asthma morbidity, [11-14] or failed to measure pulmonary function, $[6,7,11-14]$ potentially limiting the generalizability, strength and the clinical relevance of the findings.

The association between psychiatric disorders and poor asthma control and asthma-related quality of life could occur through several pathways including behavioral pathways, such as disorganized self-care and poor health behaviors; cognitive or perceptual pathways, such as biased symptom reporting or through the direct physiological effects of depression and anxiety on the autonomic nervous (ANS) and immune systems which increase asthma symptomatology.

Previous studies have found consistent relationship between psychiatric disorders, particularly mood and anxiety disorders, and increased rates of smoking, [20-22] which may complicate asthma management $[23,24]$ and quality of life [25]. There is also evidence showing that asthmatics reporting greater levels of psychological distress (e. g., anxiety, depression) misuse medication $[6,26]$. Of course, non-adherence to asthma medications has been directly linked to several indices of poor outcome, including increased use of emergency services [27] and near- fatal asthma attacks [27]. Though we did not measure medication adherence in the current study, future research should include measures of treatment adherence to help elucidate the mechanisms of poorer asthma control in asthmatics with psychiatric disorders.

Findings of worse asthma control and quality of life in asthma patients with psychiatric disorders could also have occurred through cognitive or perpetual pathways, whereby psychiatric patients may have been more likely to over-report the frequency and/or severity of asthma symptoms as a result of their negative mood states. Previous shown that psychiatric patients may "hyper-sensitive" to changes in bodily sensations, which may contribute to distorted symptom perceptions in this population [28, 29]. However, there is evidence from asthma studies showing that over perception of asthma symptoms may occur independently of emotional or psychiatric factors $[30,31]$. The fact that physicians rely so heavily upon patient self-reports of their symptoms suggests that the potential influence of negative mood states on symptom perception should be taken into account when evaluating levels of asthma control and quality of life in patients with suspected or known psychiatric morbidity.

Poorer asthma control in asthmatics with psychiatric disorders could also occur through direct effects of chronic psychological stress on the ANS and immune systems. Chronic psychological stress (as is the case in patients with psychiatric disorders) has been linked to both ANSdysregulation and reduced immunocompetence in asthmatics. Several studies 
have reported associations between certain emotional states (e. g., depression with suicidality and generalised anxiety disorder) and increased cholinergically mediated airway reactivity in asthmatics $[32,33]$.

It has also been suggested that asthmatics who experience chronic psychological stress may be in a chronic proinflammatory state. Evidence for this association comes from two studies which found that examination stress was associated with increased production of proinflammatory super oxides and increased cytokine production by lymphocytes among asthmatics [34, 35]. Although these studies suggest plausible mechanisms by which chronic psychopathology and psychological stress may affect asthma control, this research is still in its infancy and future research is needed to fully elucidate the nature and significance of these associations.

Again some of the toxic irritants that precipitate asthmatic attack, when accumulate in sufficient toxic dose can damage the brain cell particularly the limbic apparatus that controls mood. Lead exposure is of particular interest because it is an established neurotoxin with known effects on several brain systems implicated in depression and anxiety, including monoaminergic signaling.

Taken together, toxic heavy metals are found in the air we breathe, the food we eat, and the houses we live in. Toxic metal exposure can result in a wide array of common mental health disorders. Depressive illness can worsen asthmatic state. Both illnesses are associated with reduced immune cell functioning. Continuous use of steroids have equally been implicated in lowered immunity. These can further predispose the individual to recurrent infections causing greater psychological impact.

\section{Conclusion and Recommendations}

The results of this study highlight high prevalence of depression among outpatient asthmatics, and the range of eased morbidity that may be associated with it. These findings also suggest that physicians may need to consider the potential impact of negative mood states when assessing levels of asthmacontrol and implementing treatment strategies. It may be that psychiatric morbidity is associated with increased symptom perception and/or symptom reporting, which may be falsely interpreted as poor asthma control by both patients and physician Nonetheless, physicians still rely heavily upon patient reports of symptoms when making treatment decisions, and should be aware of the heightened symptomatology, greater functional impairment, and poorer asthma control in this population.

We recommend that the clinical evaluation of asthmatic patients, should importantly include their mental wellbeing. Proper awareness be created among physicians through training to increase their clinical acumen at recognising comorbid psychiatric disorder and make appropriate decision which may include referral. There is great need also for awareness of the existence of this comorbidity as well as institution of appropriate identification measures and subsequent referral for appropriate treatment. This will undoubtedly improve the management of asthmatics as well as their quality of life.

\section{References}

[1] World Health Organization: Bronchial asthma. http://www.who.int/mediacentre/factsheets/fs206/en/print.html (revised January 2000).

[2] CDC, National Center for Health Statistics. Asthma prevalence, health care use and mortality, 2000-2001. Available

at http://www.cdc.gov/nchs/products/pubs/pubd/hestats/asthma/a sthma.htm.

[3] Barnes PJ, Jonsson B, Klim JB. The costs of asthma. EurRespir J 1996; 9: 636-42.

[4] Hoskins G, McCowan C, Neville RG, Thomas GE, Smith B, Silverman R. Risk factors and costs associated with an asthma attack. Thorax 2000; 55: 19-24.

[5] Miles JF, Garden GM, Turncliffe WS, Clayton RM, Ayres JG. Psychological morbidity and coping skills in patients with brittle and non-brittle asthma: A case-control study. ClinExp Allergy 1997; 27: 1151-9.

[6] Cluley S, Cochrane GM. Psychological disorder is asthma is associated with poor control and poor adherence to inhaled steroids. Respir Med 2001; 95: 37-9.

[7] Goldney RD, Ruffin R, Fisher LJ, Wilson DH. Asthma symptoms associated with depression and lower quality of life: a population survey. Med J Aust 2003; 178: 437-41.

[8] Janson C, Bjornsson E, Hetta J, Boman G. Anxiety and depression in relation to respiratory symptoms and asthma. Am J RespirCrit Care Med 1994; 149: 930-4.

[9] Van der Schoot TA, Kaptein AA. Pulmonary rehabilitation in an asthma clinic. Lung 1990; 168: 495-501.

[10] Nejteck VA, Brown ES, Khan DA, Moore JJ, Van Wagner J, PerantieDC. Prevalence of mood disorders and relationship to asthma severity in patients at an inner-city asthma clinic. Ann Allerg Asthma Immunol 2001; 87: 129-33.

[11] Perna G, Bertani A, Politi E, Colombo G, Bellodi L. Asthma and panic attacks. Biol Psychiatry 1997; 42: 625-30.

[12] Nacimento I, Nardi AE, Valenca AM, et al. Psychiatric disorders in asthmatic outpatients. Psychiatry Res 2002; 110: 73-80.

[13] Goodwin RD, Olfson M, Shea S, et al. Asthma and mental disorders in primary care. Gen Hosp Psychiatry 2003; 25: 479-83.

[14] Goodwin RD, Jacobi F, Thefeld W. Mental disorders and asthma in the community. Arch Gen Psychiatry 2003; 60: 1125-30.

[15] Bateman ED, Boushey HA, Bousquet J, et al. Can guideline defined asthma control be achieved? The gaining optimal control of asthma study. Am J RespirCrit Care Med 2004; 170: 836-44. 
[16] Global Initiative for Asthma (GINA). Global strategy for asthma management and prevention: NHLBI/WHO Workshop Report. Bethesda: National Institutes of Health, National Heart, Lung, and Blood Institute; 2002. Publication No. 023659 .

[17] American Psychiatric Association. Diagnostic and statistical manual of mental disorders, 4th ed (DSM-IV). Washington DC: American Psychiatric Press; 1994.

[18] Kessler RC, McGonagle KA, Zhao S, et al. , Lifetime and 12month prevalence of DSM-III-R psychiatric disorders in the United States. Arch Gen Psychiatry 1994; 51: 8-19.

[19] Goodwin RD, Eaton WE. Asthma and the risk of panic attacks among adults in the community. Psychol Med 2003; 33: 87985 .

[20] Breslau N, Kilby MM, Andreski P. Nicotine dependence and major depression: new evidence from a prospective investigation. Arch Gen Psychiatry 1993; 50: 31-5.

[21] Hughes JR, Hatsukami D, Mitchell JE, Dahlgren LA. Prevalence of smoking among psychiatric outpatients. Am J Psychiatry 1986; 143: 993-7.

[22] Pohl R, Yeragani VK, Balon R, Lycaki H, McBride R. Smoking in patients with panic disorder. Psychiatry Res 1992; 43: $253-62$.

[23] Chadhuri R, Livingston E, McMahon AD, Borland TL, Thomson NC. Cigarette smoking impairs the therapeutic response to oral corticosteroids in chronic asthma. Am J RespirCrit Care Med 2003; 168: 1308-11.

[24] Mitsunobu F, Ashida K, Hosaki Y, et al. Influence of longterm cigarette smoking on immuglobulin E-mediated allergy, pulmonary function, and high-resolution computed tomography lung densitometry in elderly patients with asthma. ClinExp Allergy 2004; 34: 59-64.

[25] Martinez JA, Mota GA, Vianna ED, Filho JT, Silva GA, Rodrigues Jr AL. Impaired quality of life of healthy young smokers. Chest 2004; 125: 425-8.
[26] Bosley CM, Fosbury JA, Cochrane GM. The psychological factors associated with poor compliance with treatment in asthma. EurRespir J 1995; 8: 899-904.

[27] Boulet LP, Deschesnes F, Turcotte H, Gignac F. Near-fatal asthma: clinical and physiologic features, perception of bronchoconstriction, and psychologic profile. J Allergy ClinImmunol 1991; 88: 838-46.

[28] Hoehn-Saric R, McLeod DR, Funderburk F, Kowalski P. Somatic symptoms and physiologic responses in generalized anxiety disorder and panic disorder: an ambulatory monitor study. Arch Gen Psychiatry 2004; 61: 913-21.

[29] Moore MC, ZebbBJ. The catastrophic misinterpretation of physiological distress. Behav Res Ther 1999; 37: 1105-18.

[30] Higgs CMB, Richardson RB, Lea DA, Lewis GTR, Laszlo G. The influence of knowledge of peak flow on self- assessment of asthma. Studies with a coded peak flow meter. Thorax 1986; 41: 671-5.

[31] Rietveld S, KolkAM, Prins PJM. The influence of respiratory sounds on breathlessness in children with asthma: a symptom perception approach. Health Psychol 1997; 16: 546-53.

[32] Lehrer PM. Emotionally triggered asthma: a review of research literature and some hypotheses for self-regulation therapies. Appl Psychophysiol Biofeedback 1998; 23: 13-41.

[33] Miller BD, Wood BL. Influence of specific emotional states on autonomic reactivity and pulmonary function in asthmatic children. J Am Acad Child Adolesc Psychiatry 1997; 365: 669-77.

[34] Kang DH, Coe CL, McCarthy DO. Academic examinations significantly impact immune responses, but not lung function, in healthy well-managed asthmatic adolescents. Brain Behav Immun 1996; 10: 164-81.

[35] Kang DH, Coe CL, McCarthy DO, Ershler WB. Immune responses to final exams in healthy and asthmatic adolescents. Nurs Res 1997; 46: 112-9. 